\title{
Discontinuities in Oxidation Kinetics: A New Model and its Application to Cr-Si-Base Alloys
}

\author{
Anke S. Ulrich ${ }^{1}$ (D) - Uwe Glatzel ${ }^{2} \cdot$ Mathias C. Galetz $^{1}$
}

Received: 2 October 2020 / Revised: 19 January 2021 / Accepted: 16 March 2021 /

Published online: 27 April 2021

(C) The Author(s) 2021

\begin{abstract}
Some alloys such as many Cr-based systems show mass gain discontinuities during thermogravimetric measurements which strongly affect the oxidation kinetics. The behaviour cannot be described by the current models available in the literature. Thus, a novel $k_{\text {para }}-k_{\text {lin }}-P$-model was developed to describe oxidation kinetics during the isothermal exposure of materials which show such behaviour. Beside the parabolic rate constant $k_{\text {para }}$ and the linear mass loss constant $k_{\text {lin }}$, the $P$-value and $f_{P}$ are introduced to take into account spontaneous rapid mass gains due to local oxide scale failure. The parameter $P$ serves as a measure for the mass gain due to discontinuous events and $f_{P}$ is the frequency of such events. The both parameters can be related to oxide scale detachment and growth stresses. The application of the model is demonstrated for the oxidation of $\mathrm{Cr}$-Si-based alloys in synthetic air at $1200^{\circ} \mathrm{C}$ for $100 \mathrm{~h}$. For these alloys, the origin of the mass gain discontinuities is discussed and the meaning of $P$ and $f_{P}$ is explained in more detail. Using this newly developed model, an insight into growth and nitridation resistance of oxide scales as well as scale adhesion is gained.
\end{abstract}

Keywords Thermogravimetric analysis $\cdot$ Kinetic model $\cdot \mathrm{Cr}-\mathrm{Si}$ alloys $\cdot$ Protective scale formation $\cdot$ Nitridation

\section{Introduction}

High temperature materials always show a certain amount of degradation during exposure in oxidising or corroding environments. To decrease this degradation, such materials are designed to form protective oxide scales which have high

Anke S. Ulrich

silvia.ulrich@dechema.de

1 High Temperature Materials, DECHEMA-Forschungsinstitut, Theodor-Heuss-Allee 25, 60486 Frankfurt am Main, Germany

2 Metals and Alloys, University Bayreuth, Prof.-Rüdiger-Bormann-Str. 1, 95447 Bayreuth, Germany 
thermodynamic stability, a low growth rate, and high adherence to the underlying substrate [1]. To investigate the growth and stability of such oxide scales, cyclic or isothermal tests during which the material's mass change is recorded, are widely used. Thermogravimetric analysis (TGA) records the mass change in situ during isothermal exposure and is a standard method to identify the growth kinetics of the formed oxides. However, as shown for the oxidation of pure $\mathrm{Cr}$ in Fig. 1, the determination of growth kinetics can be challenging in the case discontinuities in TGA curves occur.

In the case of $\mathrm{Cr}$ such fast and spontaneous mass gains, called mass gain discontinuities in the following, where the rate of oxidation rises much faster in a short time than the rate for longer time periods are explained by local oxide scale failure [5-8] due to the release of growth stresses [3]. Scale spallation can occur during exposure or during cooling even though the oxide's growth kinetics are considered to show protective behaviour. Taking into account or even predicting oxide scale spallation is challenging, since it not only depends on oxide-scale adherence, but also on the intensity of stresses (growth stresses and stresses due to thermal expansion coefficient mismatch), on the thickness, mechanical properties of the oxide scale and mechanical demands on the substrate. So far the investigations in the literature, mostly refer to scale spallation caused by thermal shock; for example, the determination of the critical temperature drop before spallation occurs is determined in [9-11]. Even in the case of the more thoroughly investigated thermal stress, a gap between the measurements of physical data (oxidation kinetics, interfacial energy, growth stresses, coefficients of thermal expansion, mechanical properties of the alloy and of the oxide,...) and the cyclic-oxidation test exists and further scientific work is necessary $[12,13]$.

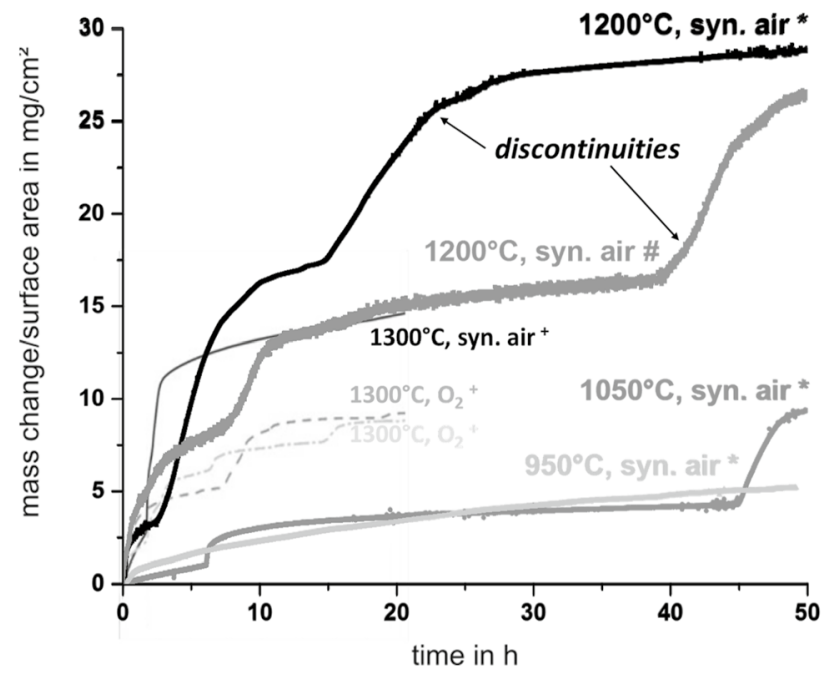

Fig. 1 Mass change measurements of pure $\mathrm{Cr}$ during oxidation in synthetic air or pure oxygen. Taken from $+[2], *[3]$, and \# [4] 
However, to the best of the authors knowledge, all known models describing oxidation kinetics do not take into account mass gain discontinuities during isothermal exposure. To meet the need for a description of materials showing intensive mass gain discontinuities during isothermal exposure, a new model-the $k_{\text {para }}$ $-k_{\operatorname{lin}}-P$-model — was developed. In this model, in addition to the well known parabolic rate constant $k_{p}$ (named $k_{\text {para }}$ ) and the linear mass loss constant $k_{v}$ (named $k_{\text {lin }}$ ) in case of the formation of volatile reaction products, the perturbation value $P$ and the perturbation frequency $f_{P}$ are introduced to quantify the mass gain discontinuities and thereby oxide scale failure. The applicability of the model and its relevance is demonstrated for the oxidation of $\mathrm{Cr}$-Si-based alloys.

\section{Parabolic and Paralinear Oxidation Kinetics}

In the field of high temperature materials parabolic oxidation kinetics of the material are desired as a sign for the formation of protective, dense, homogeneous, and slow growing oxides. In the case of parabolic oxidation kinetics, the parabolic rate constant $k_{p}$ can be determined from TGA experiments using Eq. 1 with $n=0.5$ and compared to other materials. Common oxides which grow in a parabolic manner and therefore which are considered as protective in high temperature applications are $\mathrm{Cr}_{2} \mathrm{O}_{3}, \mathrm{SiO}_{2}$, and $\mathrm{Al}_{2} \mathrm{O}_{3}$. It has to be mentioned that even though Eq. 1 refers to Wagner's parabolic rate law [14], several of Wagner's assumptions are usually not fulfilled by the oxidation of metals and alloys at high temperatures (for example the exclusive scale growth by bulk self-diffusion of ionic species as usually grain boundary diffusion is the dominating transport mechanism [15]). Especially for $\mathrm{Al}_{2} \mathrm{O}_{3}$ and $\mathrm{Cr}_{2} \mathrm{O}_{3}$ scale growth, sub-parabolic growth with $\mathrm{n}<0.5$ is found [16-18]. However, at high temperatures, it is commonly assumed that protective scale growth can be sufficiently described with $n=0.5$ [19].

$$
\frac{\Delta m}{A}=\left(k_{p} \cdot t\right)^{n}
$$

$\Delta m=$ mass change, $A=$ surface area, $t=$ time, $n=$ exponent generally $\leq 0.5$.

$k_{p}$ in units of $\frac{g^{2 / n}}{\mathrm{~cm}^{4 / n} s}$ is understood as a constant for the oxide formation of a certain material, however, the values scatter, for example for the oxidation of pure $\mathrm{Cr}$, by two orders of magnitude at temperatures above $1000^{\circ} \mathrm{C}$ [20]. In this case, deviation from ideal bulk self-diffusion controlled oxide growth by ionic species and vacancies $[21,22]$ plays a minor role. The main reason is that several other phenomena may occur:

- evaporation effects [23-25]

- the formation of other species such as $\mathrm{Cr}_{2} \mathrm{~N}$ at $\mathrm{T} \geq 1000^{\circ} \mathrm{C}$ [26-28]

- experimental factors such as surface roughness, gas flow [5, 21, 29, 30], gas composition $[2,3,30]$

- the substrate material composition and microstructure (impurities in the material [31-33], grain orientation, grain size [34]) 
- the appearance of the oxide scale (short circuit diffusion paths [15, 31], grain boundaries and size $[5,35,36]$, cracks, scale wrinkling, delamination, spallation of oxide scale $[3,6])$

- different techniques to determine $k_{p}$ (for example TGA [37, 38], oxide scale thickness measurements [20,39], or theoretical calculations based on diffusion constants [34])

- increase in surface area by oxide growth and wrinkling

One huge improvement in describing the oxidation kinetics of materials which form additional volatile species is the assumption of paralinear kinetics rather than parabolic kinetics. In this case, the mass gain following parabolic kinetics and the mass loss following linear kinetics are superimposed. Such kinetics can be described with Tedmons paralinear rate law for scale thickness [40] which can be transferred into the technical approach describing the mass gain shown in Eq. 2 [41]. In comparison to Eq. $1 n$ is set to 0.5 in this case. For $\mathrm{Cr}$ and its alloys mass loss due to evaporating species becomes relevant at temperatures greater than $1000^{\circ} \mathrm{C}$ and close to normal pressure [7, 42-46] because volatile species such as $\mathrm{CrO}_{3}$ form as well as solid $\mathrm{Cr}_{2} \mathrm{O}_{3}$ [23-25]. For a more detailed discussion of the difference between this technical approach and Tedmon's theory with respect to $\mathrm{Cr}$ and its alloys the reader is refereed to [28].

$$
\frac{\Delta m}{A}=\left(k_{p} \cdot t\right)^{0.5}-k_{v} \cdot t
$$

$k_{v}=$ volatilisation rate in unit of $\frac{g}{\mathrm{~cm}^{2} s}$

\section{The $k_{\text {para }}-k_{\text {lin }}-P-$ Model}

Based on the experimental observation (compare Fig. 1) schematics of paralinear oxidation kinetics with one or more mass gain discontinuities are shown in Fig. 2. In addition, the related appearance of the oxide scale and the proposed mechanism of scale healing is schematically shown in Figure 3. The different steps

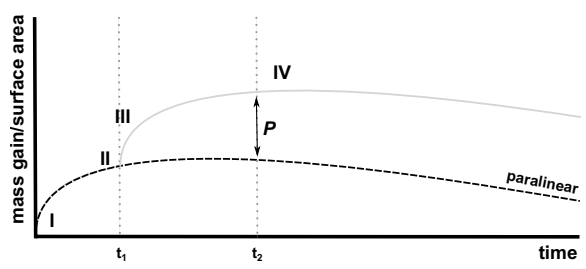

(a)

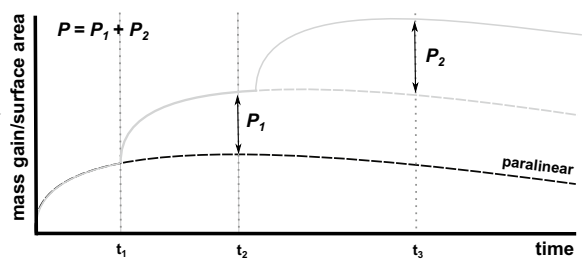

(b)

Fig. 2 Schematic of oxidation kinetics $\mathbf{a}$ with one and $\mathbf{b}$ with two mass gain discontinuities in oxidising atmospheres. (I) marks the kinetics at the beginning of exposure, II) shortly before the mass gain discontinuity, (III) the rapid mass gain during the discontinuity, and (IV) the kinetics after time $t_{2}$. A schematic of the mechanism can be found in Fig. 3. $P$ refers to the shift of the paralinear oxidation kinetics due to the discontinuities 


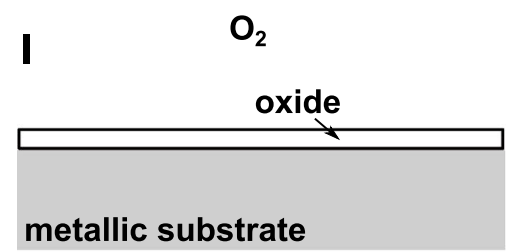

(a) initial oxide growth

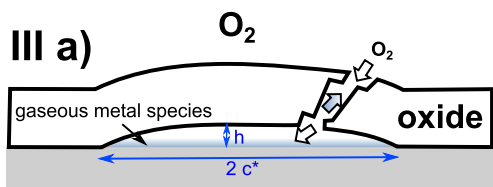

metallic substrate

(c) crack formation

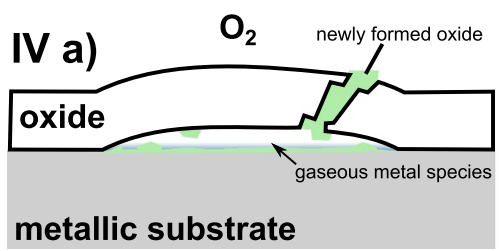

(e) oxide growth after crack formation

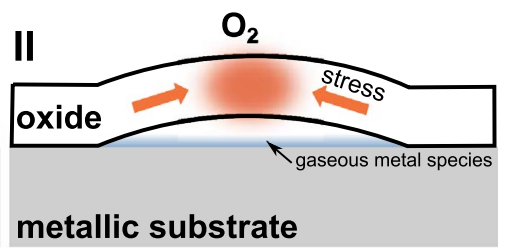

(b) scale detachment and gap formation

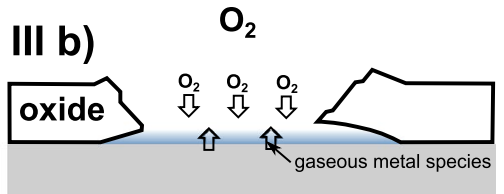

metallic substrate

(d) areal scale spallation

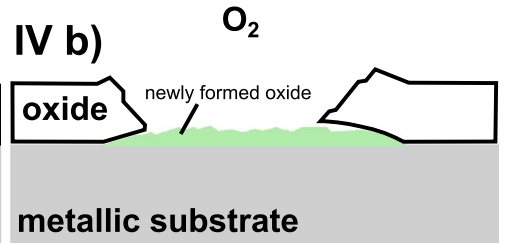

(f) oxide growth after scale spallation

Fig. 3 Mechanism of oxide scale appearance in the case of oxide growth kinetics with spontaneous rapid mass gains in oxidising atmospheres. The steps are correlated to the kinetics shown in Fig. 2. A detailed description can be found in the text. Up from step III it is distinguished between the two failure mechanisms occurring during isothermal exposure in an oxidising environment: a crack formation and $\mathbf{b}$ areal scale spallation. In addition in Fig. $3 \mathrm{c}$ length and height of the blister are marked with $2 c^{*}$ and $h$, respectively. (Color online)

marked with I-IV in Fig. 2a are explained in the following: (I) At the beginning of exposure a thin oxide scale forms following paralinear kinetics as described in Eq. 2. Due to the formation of a continuous barrier between metallic substrate and surrounding reactive atmosphere, the oxide scale growth slows down with exposure time. (II) Due to growth stresses the oxide detaches from the metallic substrate and scale wrinkling occurs. In the case certain elements in the metallic substrate exhibit high partial pressures (e.g. Cr), the gap between metal and oxide is filled with gaseous metal species which are not oxidised due to the low oxygen partial pressure below the oxide scale. (III) Subsequently, increasing stress leads to scale failure. Two possible failure mechanisms are shown schematically marked with a) crack formation or b) areal scale spallation in Fig. 3. Scale failure at exposure time $t_{1}$ leads to local, time-limited exposure of the metal surface to the surrounding atmosphere and therefore to a rapid reaction of metal and atmosphere. Rapid mass gain occurs comparable to the beginning of the exposure until the oxide scale is fully closed again. IV) After $t_{2}$ the scale has fully closed again and the scale growth is comparable to a scale without crack formation. The scale 
growth rate is comparable to that of an ideal paralinear growth without the occurrence of a mass gain discontinuity (compare dotted curve in Fig. 1).

As shown schematically in Fig. 2 and in the experimentally determined TGA curves in Fig. 1, the sum of rapid mass gains over the whole oxidation time leads to a shift of the mass change per time curves towards higher mass change/surface area values. In the newly developed model, the total offset is called the $P$-value and it is assumed that this rapid mass change has no effect on the intrinsic kinetics of the oxide growth up from a certain time ( $t_{2}$ and $t_{3}$ in Fig. 2$)$. The latter is taken into account by determining the parabolic rate constant and the linear mass loss constant from Eq. 2 after subtracting $P$, hence, independently of the mass gain discontinuities (dotted black curves in Fig. 2). To mark the use of the newly developed model, $k_{p}$ and $k_{v}$ are renamed to $k_{\text {para }}$ and $k_{\text {lin }}$, respectively. The overall mass gain from the discontinuities is given by $P_{t}$ after oxidation time $t$. The frequency of perturbation over oxidation time is given by $f_{P}$. By introducing both parameters, two new measures for investigating the oxide scale attachment and the induced growth stresses can be obtained from TGA measurements and be used to describe and compare different behaviours.

The assumptions made to determine the parameters of the $k_{\text {para }}-k_{\text {lin }}-P$-model can be summarised as follows:

1. The mass gain discontinuities are caused by local oxide scale failure.

2. The oxide scale is fully closed after the discontinuity (step IV in Fig. 3).

3. During a discontinuity, rapid mass gain occurs but is not an intrinsic change of the overall oxide growth mechanism (step IV in Fig. 2a).

4. The growth of the newly formed oxide follows paralinear growth kinetics [3, 45, 47]. After a discontinuity the mass change again follows paralinear kinetics after a certain time $\left(t_{2}, t_{3}\right)$ as schematically shown in Fig. 2, step IV [3, 45, 47]).

\section{Explanation of Model Parameters}

\section{Parabolic Mass Gain}

In contrast to Wagner's theory and to oxidation kinetics descriptions using Eqs. 1 or 2 , the parabolic rate constant in the $k_{\text {para }}-k_{\text {lin }}-P$-Model is a superimposition of all mechanisms leading to parabolic mass gain. To point out this difference, the parameters are named with $k_{\text {para }}$ and $k_{\text {lin }}$ instead of $k_{p}$ and $k_{v}$.

\section{Linear Mass Loss}

Evaporation of volatile species is assumed to follow a linear rate law which is taken into account by $-k_{v} \cdot t$ in Eq. 2. For detailed investigations of the effects of gas flow, pressure, gas composition, and the comparison of different rates the reader is referred to [48-51]. In this work, it is assumed that also the superimposition of all volatile species formed follows linear kinetics. 


\section{The $P$-value}

$P$ is a measure for the mass gain as well as for the volume of the gap which formed at the metal/oxide interface by scale wrinkling and buckling during isothermal exposure. Assuming a circular shaped defect, more specifically a spheroid, the volume of the gap can be determined by (compare Fig. 3c):

$$
V_{\text {gap }}=\frac{4 \pi}{3} c^{* 2} \cdot h
$$

$c^{*}=$ effective defect radius, $h=$ gap height.

$c^{*}$ is comparable to the critical defect size of blisters after Griffith theory of fracture as it is used in calculating the oxide scale failure due to stresses in the oxide scale [52]. Similarly, the effective defect size is not only the physical defect size but also includes interactions with several defects in the case they are adjacent to each other [53]. Beside oxides, the $P$-value also depends on the formation of other species leading to mass gains i. e. carbides or nitrides. Hence, $P$ is directly proportional to the concentration of oxygen in the surrounding atmosphere (given by $p\left(\mathrm{O}_{2}\right)$ ) and the concentration of other reactive species which could cause a mass gain (e.g. $\mathrm{CO}$ or $\mathrm{N}_{2}$ ). The effect of such reactive species can be assessed with their total partial pressure $p\left(R_{\text {gas }}\right)$. Furthermore, in the case of the predominant formation of oxide species which are conventionally considered to be protective, the closing time $t_{\text {close }}\left(p\left(\mathrm{O}_{2}\right)\right)$ of the crack is inversely proportional to the oxygen partial pressure as more oxygen available which enhances the reaction and leads to faster crack closing. And the faster the crack is closed, the less the reactive species, including $\mathrm{O}_{2}$, can be in contact with the metal surface. Hence, $P$ is proportional to the time until the crack closes $\left(t_{\text {close }}\left(p\left(\mathrm{O}_{2}\right)\right)\right)$ and in turn also inversely proportional to the oxygen partial pressure $p\left(\mathrm{O}_{2}\right)$. Using Eq. 3, this leads to following relationship for the mass gain during one mass gain discontinuity:

$$
\begin{aligned}
P_{1 \text { Pert }} & =K_{1} \cdot V_{\text {gap }} \cdot\left(p\left(R_{\text {gas }}\right)+p\left(O_{2}\right)\right) \cdot t_{\text {close }}\left(p\left(O_{2}\right)\right) \\
& =K_{2} \cdot \frac{4 \pi c^{* 2} \cdot h \cdot\left(p\left(R_{\text {gas }}\right)+p\left(O_{2}\right)\right)}{3 \cdot p\left(\mathrm{O}_{2}\right)}
\end{aligned}
$$

$K_{1,2}=$ constants

$p\left(\mathrm{O}_{2}\right)=$ oxygen partial pressure in the surrounding atmosphere

$p\left(R_{\text {gas }}\right)=$ partial pressure of reactive species (excluding oxygen) in the surrounding atmosphere

$P_{t}$ after a defined time $t$ is given by the summation of all individual mass gain discontinuities (Eq. 4) with:

$$
P_{t}=\sum_{i=0}^{n} P_{1 \text { Pert }, i}
$$

$n=$ number of mass gain discontinuities until time $t$

Including this into Eq. 2, the overall mass gain at a specific time $t$ can be determined by: 


$$
\frac{\Delta m}{A}(t)=\left(k_{\text {para }} \cdot t\right)^{0.5}-k_{\text {lin }} \cdot t+P_{t}(t)
$$

The frequency $f_{P}$ of the rapid mass gains is an important additional parameter. It is a measure for how often a critical stress is reached in the oxide scale as well as for the attachment of the scale. However, with respect to the $k_{\mathrm{para}}-k_{\mathrm{lin}}-P$-model this parameter is not necessary to determine the overall mass change during exposure. $f_{P}$ is understood as a measure which can be used to obtain more insight into the microscopic events leading to mass gain discontinuities. The frequency is important to consider, for example, in the case of investigations aiming to improve oxide scale adhesion by alloying. $f_{P}$ depends on the growth stresses in the oxide scale and the metal/oxide interface energy and can be therefore be described with:

$$
f_{P}=\frac{\# P}{t}=K_{2} \cdot \frac{\sigma_{c}}{\gamma_{i}}
$$

$\# P=$ number of mass gain discontinuities over time $t, K_{2}=$ constant, $\gamma_{i}=$ interface energy metal/oxide, $\sigma_{c}=\frac{K_{I c}}{f \sqrt{\pi c}}=$ critical stress as calculated in [54], $K_{I c}=$ fracture toughness, $c=$ effective length of the defect, $f=$ geometric constant (usually $\approx 1$ ).

\section{Distinction from Other Models}

In contrast to other models describing the mass change over oxidation time, the $k_{\text {para }}-k_{\text {lin }}-P$-model is used to describe oxide scale failures (spallation and cracking) during isothermal exposure. Other models and algorithms which are used for material lifetime predictions and which take into account scale spallation, such as COSP (Cyclic Oxidation Spalling Program) $[55,56]$ and the $p-k_{p}$-model [57], refer to cyclic oxidation tests and spallation during cooling which is caused by thermal stresses. COSP is based on experiences with the oxidation behaviour of many NiAl-, $\mathrm{NiCrAl}$, and superalloys. During several years of work the mechanism of oxidation and oxide scale spallation during cyclic exposure was investigated and important variables, later included into the COSP model, were identified [58-61]. The model is based on the assumptions (i) of a constant area of spalled oxide per oxidation cycle, (ii) parabolic growth of the oxide scale, and (iii) that spallation only occurs at the metal/oxide interface. However, it was also shown that the spalled area is a function of oxide thickness and therefore of exposure time which leads to inaccuracies. Spontaneous oxide scale spallations can be included in the model using Monte Carlo simulations and Poquillon's $p-k_{p}$-model describes scale failure at the substrate/oxide interface during cyclic exposure. The oxide growth is assumed to follow a parabolic rate law with the parabolic rate constant $k_{p}$ and the constant $p$, the probability for oxide spalling.

The software COREST describes the oxidation kinetics of $\mathrm{Cr}_{2} \mathrm{O}_{3}$ formers during isothermal exposure [62]. Originally, it was developed for lifetime predictions of materials showing paralinear oxidation kinetics. Oxide scale spallation is also taken into account but not as spontaneous events which are described by an additional 
parameter but rather as a part of the overall determined $k_{p}$ and $k_{v}$ values. A comparable method for determining $k_{p}$ and $k_{v}$ of the oxidation of $\mathrm{Cr}$ during exposure at high temperatures was used in several previous studies [19,39]. The mass change curves were fitted by a paralinear term over the duration of the experiment despite rate changes during rapid mass gain discontinuities. This approach results in higher $k_{p}$ (and $k_{v}$ ) values compared to those determined in this work by the $k_{\text {para }}-k_{\operatorname{lin}}-P$-model which not only considers reactions leading to parabolic growth. To handle this problem, other authors solely used the time to the first mass gain discontinuity to characterise the paralinear kinetics $[45,63]$. However, the oxide scale detachment from the metal cannot be described in this case as it is done using the value $P$.

The main difference between the $k_{\text {para }}-k_{\text {lin }}-P$-model and previous models is the consideration of scale spallation as a statistical event during isothermal exposure which is no longer restricted to cooling events. $P$ and $f_{P}$ can now be used as additional parameters to quantify the influence of scale detachment and spallation on kinetics. The influence of different alloying elements on the oxidation resistance of $\mathrm{Cr}$ and its alloys can be investigated in more detail. Additionally, $P$ is not limited to spallation events at the metal/oxide interface, but all scale failures which lead to mass gain discontinuities are taken into account.

\section{Relevance for Cr-Base Alloys}

While pure $\mathrm{Cr}$ is not relevant for many industrial applications, $\mathrm{Cr}$-alloys especially based on the $\mathrm{Cr}$-Si-system are considered as promising candidates to withstand working temperatures of high temperature applications beyond the commonly used Ni-base superalloys. In this work, the determination of oxide growth kinetics using the $k_{\text {para }}-k_{\text {lin }}-P$-model is exemplified shown for oxidation tests of pure $\mathrm{Cr}$ and the alloys $\mathrm{Cr}_{91} \mathrm{Si}_{9}, \mathrm{Cr}_{91} \mathrm{Si}_{7} \mathrm{Ge}_{2}, \mathrm{Cr}_{91} \mathrm{Si}_{7} \mathrm{Pt}_{2}$, and $\mathrm{Cr}_{91} \mathrm{Si}_{7} \mathrm{Mo}_{2}$ (in at.\%) at $1200^{\circ} \mathrm{C}$ in synthetic air. The microstructure and the oxidation performance of these alloys is already discussed elsewhere $[4,64,65]$. In Cr-based alloys not only the appearance of discontinuous mass gains but additionally, the formation of other phases beside $\mathrm{Cr}_{2} \mathrm{O}_{3}$ occurs. In oxidising atmospheres additional $\mathrm{SiO}_{2}$ forms at the scale/metal interface $[45,66]$. Depending on the alloy composition (at $1200^{\circ} \mathrm{C}$ with more than 7 at.\% $\mathrm{Si}$ [4]) an additional oxide layer of $\mathrm{SiO}_{2}$ arises. Furthermore, the formation of brittle $\mathrm{Cr}_{2} \mathrm{~N}$ in the subsurface region below oxide scales is a well-known characteristic from oxidation experiments of $\mathrm{Cr}$-based alloys in nitrogen containing atmospheres such as air at $\mathrm{T}>1000^{\circ} \mathrm{C}[20,67]$. The latter is understood as one of the main drawbacks of Cr-based alloys for their consideration as structural materials in high temperature applications. Hence, the formation of other species besides $\mathrm{Cr}_{2} \mathrm{O}_{3}$ have to be included in a model to consider oxidation kinetics and the amount of material attack. As the formation of a pure $\mathrm{SiO}_{2}$ scale as well as inner oxidation follows a parabolic law $[1,68]$, the formation of $\mathrm{SiO}_{2}$ on $\mathrm{Cr}-\mathrm{Si}$-based alloys is covered by $k_{\text {para }}$. The higher thermodynamic stability of $\mathrm{SiO}_{2}$ but the lower concentration of $\mathrm{Si}$ in the alloy leads to the formation of $\mathrm{SiO}_{2}$ in the region of a lower oxygen partial pressure, which is below the stability of $\mathrm{Cr}_{2} \mathrm{O}_{3}$. As its formation still depends on oxygen diffusion through the scale, $\mathrm{SiO}_{2}$ also grows continuously. On the contrary, 
the mechanism of $\mathrm{Cr}_{2} \mathrm{~N}$ formation on $\mathrm{Cr}$ and its alloys and therefore its influence on the kinetics is still under debate. In this case, the application of the $k_{\text {para }}-k_{\operatorname{lin}}-P$-model led to further insight which will be described later.

Additionally, the formation of volatile species such as $\mathrm{CrO}_{3}, \mathrm{Cr}$, and in wet atmospheres $\mathrm{CrO}_{2}(\mathrm{OH})_{2}$ and $\mathrm{CrO}_{2}(\mathrm{OH})$ is covered by the parameter $k_{\text {lin }}$. Considerable amounts of volatile $\mathrm{CrO}_{3}$ form at temperatures higher than $1000^{\circ} \mathrm{C}$ [23]. In the presence of water vapour, $\mathrm{H}_{2} \mathrm{O}$ reacts with $\mathrm{Cr}_{2} \mathrm{O}_{3}$ forming volatile chromium oxyhydroxides measurable in the weight change at temperatures higher than $600^{\circ} \mathrm{C}$ [69]. This reaction follows linear mass loss kinetics [70, 71] and affects $\mathrm{Cr}$ depletion in combustion environments [72]. Furthermore, $\mathrm{Cr}$ has a high vapour pressure itself. For example, at temperatures above $825^{\circ} \mathrm{C}$ and normal pressure the $\mathrm{Cr}$ partial pressure at the oxide/metal interface is comparable to the partial pressure of $\mathrm{CrO}_{3}$ at the oxide/gas interface [37, 73]. Hence, the evaporation of $\mathrm{Cr}$ also has to be taken into account at least at low oxygen partial pressures. It has to be mentioned that the transport of volatile $\mathrm{Cr}$ species which form in the $\mathrm{Cr} / \mathrm{Cr}_{2} \mathrm{O}_{3}$ gap is rather fast and does not affect the oxide growth rate and therefore the parabolic oxidation constant $k_{\text {para }}$ at temperatures above $1000^{\circ} \mathrm{C}[6]$.

\section{Application of the Model}

TGA measurements at $1200^{\circ} \mathrm{C}$ published in [4] are shown in Figs. 4 and 5 for different $\mathrm{Cr}$ alloys. In addition, so-called modified curves are displayed. These curves were obtained by subtracting the mass gains caused by perturbation events. For the modification, the rapid mass change per surface area is measured on each discontinuity step as demonstrated for the $\mathrm{Cr}_{91} \mathrm{Si}_{9}$ alloy in Fig. 4. The curve is fitted linearly

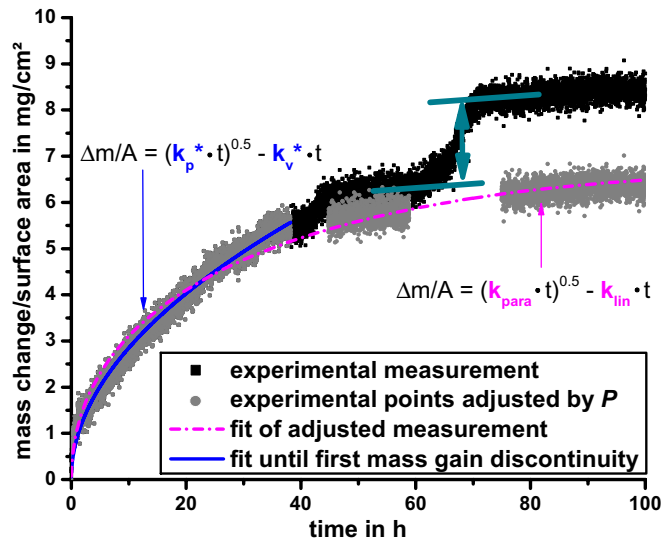

Fig. 4 TGA measurements of the $\mathrm{Cr}_{91} \mathrm{Si}_{9}$ alloy at $1200^{\circ} \mathrm{C}$ in synthetic air, after [74]. The original measurement (named experimental measurement here) is shown as well as the experimental points modified by subtracting $P$ to apply the $k_{\text {para }}-k_{\text {lin }}-P$-model. In green, the linear fits on both sides of one mass gain discontinuity are added to show how the $P$-value was determined. Additionally, paralinear fits which were used to determine the paralinear constants $k_{p}$ and $k_{v}$ using equation are added 2 . Note that the rate constants are named differently according to the used fitting method. (Color online) 


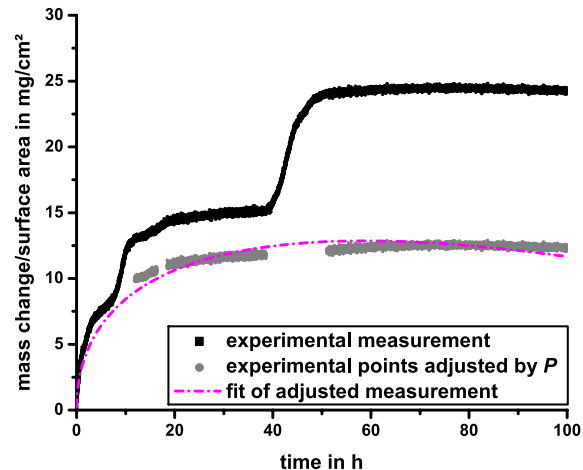

(a) $\mathrm{Cr}$

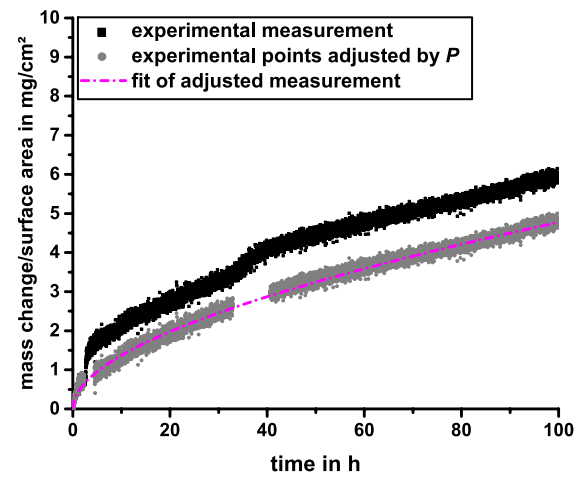

(c) $\mathrm{Cr}_{91} \mathrm{Si}_{7} \mathrm{Pt}_{2}$

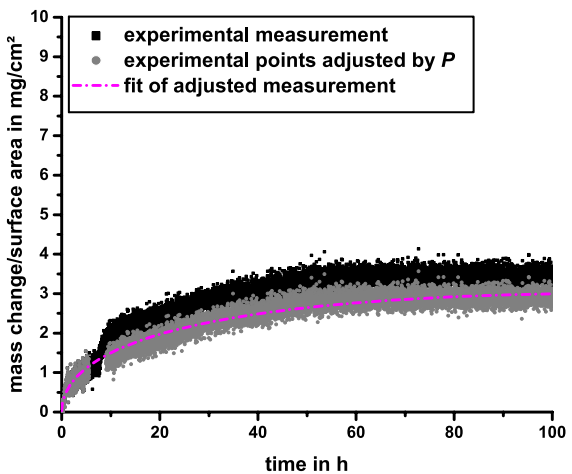

(b) $\mathrm{Cr}_{91} \mathrm{Si}_{7} \mathrm{Ge}_{2}$

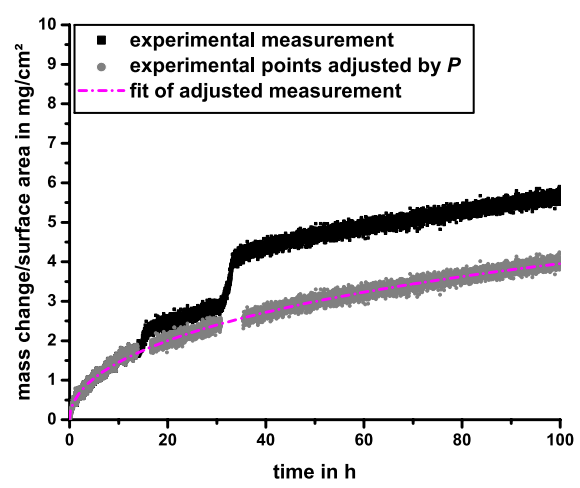

(d) $\mathrm{Cr}_{91} \mathrm{Si}_{7} \mathrm{Mo}_{2}$

Fig. 5 TGA measurements at $1200^{\circ} \mathrm{C}$ in synthetic air from [4, 74]. The investigation of the oxidation kinetics by using the $k_{\text {para }}-k_{\operatorname{lin}}$-model is demonstrated for several alloys in this figure by showing the original measured curves (experimental measurement) as well as the modified curves (experimental points adjusted by $P$ ) and the final paralinear fits of the adjusted experimental curve. (Color online)

on both sides-left and right (green) — of the mass gain discontinuity and mass gain offset is determined at a certain time. The values of all offsets appearing during one thermogravimetric measurement (in this case during $100 \mathrm{~h}$ ) are summarised and referred to as the $P_{100}$ value in the following. The modified curves are fitted using the assumption of paralinear oxidation kinetics (Eq. 2) after removal of the discontinuities as it is demonstrated in Figs. 4 and 5 for several $\mathrm{Cr}-\mathrm{Si}$-based alloys.

In Table 1, the fit parameters are listed. In [4] the paralinear oxidation parameters $k_{p}^{*}$ and $k_{v}^{*}$ of the same TGA measurements were determined by fitting the mass gain characteristics to the first mass gain discontinuity assuming paralinear kinetics (Eq. 2). These values are marked with * in the following. Additionally, the parameters $k_{\text {para }}, k_{\text {lin }}, P_{100}$, and $f_{P}$ are listed which were determined using the $k_{\text {para }}-k_{\text {lin }}-P$-model. All parameters are compared in Table 1 . The influence of $\mathrm{Si}, \mathrm{Ge}, \mathrm{Mo}$, or $\mathrm{Pt}$ on the oxidation kinetics and performance are described in detail elsewhere [4] as this publication focuses on the different 
Table 1 Overview of the fit parameters obtained using the $k_{\text {para }}-k_{\operatorname{lin}}-P$-model and other fit approaches based on Eq. 2

\begin{tabular}{|c|c|c|c|c|c|}
\hline \multirow{2}{*}{$\begin{array}{l}\text { Used approach } \\
\text { Alloy }\end{array}$} & \multicolumn{5}{|c|}{$k_{\text {para }}-k_{\text {lin }}-P$-model: $\frac{\Delta m}{A}=\left(k_{\text {para }} \cdot t\right)^{0.5}-k_{\text {lin }} \cdot t$} \\
\hline & $\begin{array}{l}k_{\text {para }} \text { in } \\
10^{-11} \mathrm{~g}^{2} \mathrm{~cm}^{-4} \mathrm{~s}^{-1}\end{array}$ & $\begin{array}{l}k_{\text {lin }} \text { in } \\
10^{-9} \mathrm{gcm}^{-2} \mathrm{~s}^{-1}\end{array}$ & $\begin{array}{l}P \text { in } \\
10^{-3} \mathrm{gcm}^{-2}\end{array}$ & $f_{P 100 h}$ in $10^{-2} h^{-1}$ & Adj. $\mathbf{R}^{2}$ \\
\hline $\mathrm{Cr}$ & 312.9 & 60.8 & 11.9 & 3 & 0.92 \\
\hline $\mathrm{Cr}_{91} \mathrm{Si}_{9}$ & 35.8 & 13.5 & 2.1 & 2 & 0.97 \\
\hline $\mathrm{Cr}_{91} \mathrm{Si}_{7} \mathrm{Ge}_{2}$ & 8.6 & 7.1 & 0.7 & 1 & 0.93 \\
\hline $\mathrm{Cr}_{91} \mathrm{Si}_{7} \mathrm{Mo}_{2}$ & 6.7 & 2.6 & 1.7 & 2 & 0.99 \\
\hline $\mathrm{Cr}_{91} \mathrm{Si}_{7} \mathrm{Pt}_{2}$ & 4.7 & -1.8 & 1.1 & 2 & 0.99 \\
\hline Used approach & \multicolumn{5}{|c|}{ Paralinear fit until first mass gain discontinuity: $\frac{\Delta m}{A}=\left(k_{p}^{*} \cdot t\right)^{0.5}-k_{v}^{*} \cdot t$} \\
\hline Alloy & $\begin{array}{l}k_{p}^{*} \text { in } \\
10^{-11} \mathrm{~g}^{2} \mathrm{~cm}^{-4} \mathrm{~s}^{-1}\end{array}$ & $\begin{array}{l}k_{v}^{*} \text { in } \\
10^{-9} \mathrm{gcm}^{-2} \mathrm{~s}^{-1}\end{array}$ & Adj. $\mathbf{R}^{2}$ & & \\
\hline $\mathrm{Cr}$ & 323.9 & 0 & 0.92 & & \\
\hline $\mathrm{Cr}_{91} \mathrm{Si}_{9}$ & 23.2 & 2.3 & 0.96 & & \\
\hline $\mathrm{Cr}_{91} \mathrm{Si}_{7} \mathrm{Ge}_{2}$ & 9.4 & 14.2 & 0.75 & & \\
\hline $\mathrm{Cr}_{91} \mathrm{Si}_{7} \mathrm{Mo}_{2}$ & 6.3 & 0 & 0.96 & & \\
\hline $\mathrm{Cr}_{91} \mathrm{Si}_{7} \mathrm{Pt}_{2}$ & 4.1 & -24.0 & 0.82 & & \\
\hline
\end{tabular}

The constants are named differently depending on the approach which was used. $k_{\text {para }}$ and $k_{\text {lin }}$ were obtained using the newly developed model, $k_{p} *$ and $k_{v} *$ were taken from [4] by fitting until the first mass gain discontinuity. For a visualisation of the different fit approaches, it is referred to Fig. 4

models to describe oxidation kinetics. For an improved visualisation both paralinear constants are shown in Fig. 6a, b. It is found that the different kinetics parameters - the ones determined using the $k_{\text {para }}-k_{\text {lin }}-P$-model and the ones from [4] determined assuming paralinear kinetics up to the first mass gain discontinuity (denominated with *) - only differ slightly. Comparing the determined $k_{\text {lin }}$ and $k_{v}^{*}$ parameters in Table 1 it is found that they differ strongly in contradiction to $k_{\text {para }}$ and $k_{p}^{*}$. Additionally, the evolution of the mass loss rate $k_{\text {lin }}$ over time is displayed in Fig. 6c. Therefore, the experimental measurement was modified by subtracting $P$. Subsequently, the curves were fitted up to selected times (x-axis in Fig. 6c) using Eq. 2. With this method, $k_{\text {lin }}$ was determined after different times. Interestingly, a convergence of $k_{\text {lin }}$ over time is found for each alloy which slightly differs depending on the alloy composition. No values are shown for the $\mathrm{Cr}_{91} \mathrm{Si}_{7} \mathrm{Pt}_{2}$ composition as this alloy tends to show rather linear mass gain kinetics instead of mass loss (for a more detailed description and investigation see [4]). 


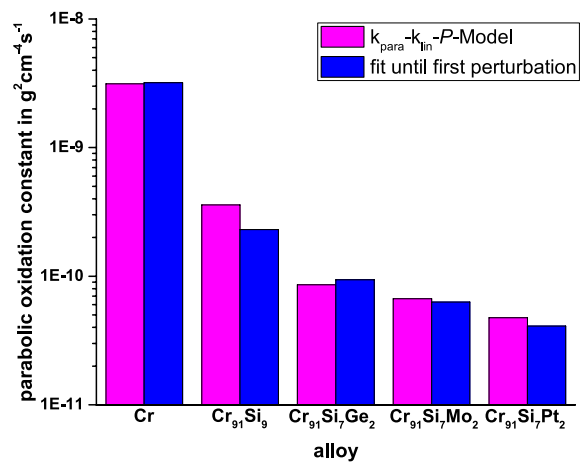

(a) $k_{p}$

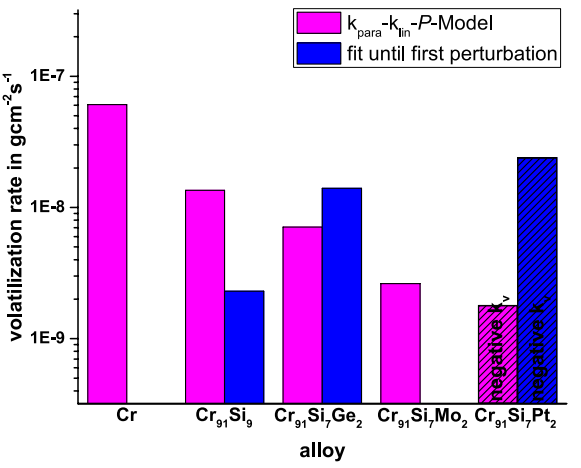

(b) $k_{v}$

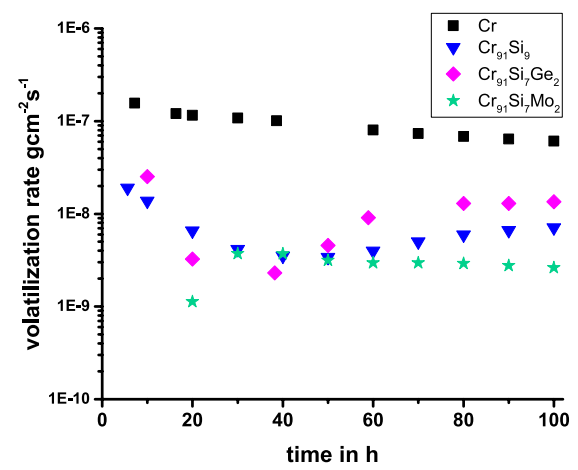

(c) $k_{\text {lin }}$ evolution

Fig. 6 In $6 \mathrm{a}$ and $6 \mathrm{~b}$ the differently determined $k_{p}$ and $k_{v}$ values are shown for all analysed alloy compositions. These figures visualise the values listed in Table 1 which were determined using different approaches. In $6 \mathrm{c}$ the volatilisation rate determined by fitting the experimental points adjusted by $P$ up to a certain time is shown for different alloys. This graph displays the convergence of $k_{\text {lin }}$ over time for each alloy composition. (Color online)

\section{New Insights Gained into Oxidation Mechanisms of Cr-Alloys Using the $k_{\text {para }}-k_{\text {lin }}-P$-Model}

\section{Parabolic Rate Constant}

As shown in Fig. 6a $k_{\text {para }}$ and $k_{p}^{*}$ only differ slightly. Hence, the parabolic rate constant determined up to the first mass gain discontinuity is comparable to the parabolic rate constant determined using the $k_{\text {para }}-k_{\text {lin }}-P$-model and measurements up to $100 \mathrm{~h}$ of oxidation in this case. To explain these findings, the insights gained into the mechanism of oxidation and nitridation of $\mathrm{Cr}$ and its alloys will be shortly reviewed and discussed in more detail.

Recently, it was proposed that $\mathrm{N}$-transport through the oxide scale is controlled by molecular $\mathrm{N}_{2}$ transport via microcracks and defects in the oxide scale rather than by diffusion controlled transport $[2,8]$. For the molecular transport, two mechanisms 
are described [8]: i) dynamic micro-crack formation-healing process which is a continuous process of microcrack formation and healing and ii) wrinkling mechanism which is based on the deformation of the oxide scale. Interestingly, only $\mathrm{Cr}_{2} \mathrm{O}_{3}$ and no $\mathrm{Cr}_{2} \mathrm{~N}$ could be detected until the first mass discontinuity [8], hence, the $\mathrm{Cr}_{2} \mathrm{O}_{3}$ scale seems to be intrinsically protective against nitrogen. This results in the conclusion that $\mathrm{Cr}_{2} \mathrm{~N}$ forms during scale spallation and during the recorded mass gain discontinuities rather than continuously during the whole exposure time. Previous investigations on $\mathrm{Cr}$ alloyed with reactive element oxides support the theory of an intrinsically protective $\mathrm{Cr}_{2} \mathrm{O}_{3}$ scale [75]: Cr alloys with low additions of reactive elements showed a correlation between oxide scale attachment and nitridation; a scale with increased attachment to the metal substrate was found to lead to lower nitridation. Furthermore, TGA measurements of $\mathrm{Cr}_{99.9} \mathrm{Zr}_{0.1}$ (in at.\%) alloy for $20 \mathrm{~h}$ at $1050^{\circ} \mathrm{C}$ in synthetic air showed no mass gain discontinuity even though the oxide scale was mostly detached from the surface and wrinkled. Only after longer exposure times and after recorded mass gain discontinuities a $\mathrm{Cr}_{2} \mathrm{~N}$ layer was found in the subsurface region.

To sum up these findings regarding the exposure of Cr-based alloys to synthetic air:

- rapid mass gain discontinuities are only attributed to a scale cracking event as it is shown in Figs. 2 and 3

- the parabolic rate constant $k_{\text {para }}$ (or $k_{p}^{*}$ in the case of fitting mass change curves until the first mass gain discontinuity) solely refers to the oxide scale growth and excludes $\mathrm{Cr}_{2} \mathrm{~N}$ formation.

The advantage of determining the parabolic rate constant with the newly developed $k_{\text {para }}-k_{\text {lin }}-P$-model is that, depending on the time until the first mass gain discontinuity occurs, more measurement points are available for fitting which in turn increases the accuracy.

\section{Volatilisation}

Comparing the determined $k_{\text {lin }}$ and $k_{v} *$ parameters in Table 1 , it is found that they differ strongly in contradiction to $k_{\text {para }}$ and $k_{p} *$. A tendency of the linear volatilisation rates to converge over time is found for the majority of the investigations (compare Fig. 6c). There is a certain time threshold above which a sufficiently exact and constant volatilisation rate can be determined, since, the evaporation rate can only be determined after comparable long oxidation times. This observation has to be investigated in more detail in future. The reason for the occurrence of such different evaporation constants is due to more accurate fitting (existence of more data points) in the first place but also due to large oxide growth at the beginning of oxidation which suppresses the determination of other effects such as evaporation. Using the $k_{\text {para }}-k_{\text {lin }}-P$-model for describing oxidation kinetics no longer a fit until the first mass gain discontinuity (which sometimes happens after less then $10 \mathrm{~h}$ ) is taken into account but a much longer time, the whole TGA measurement which is in this case 
$100 \mathrm{~h}$. This improves the comparability of the evaporation constants and therefore the investigation of the effect of volatile oxide species formation during oxidation.

\section{Mass Gain Discontinuities}

Solimani et al. [8] recently investigated the phase formation in the surface region of pure $\mathrm{Cr}$ during the exposure at $1050^{\circ} \mathrm{C}$ in laboratory air using XRD in combination with dilatometry to measure the length change. An increase in phase fraction of 1.5 wt. $\%$ and 9 wt. $\%$ for $\mathrm{Cr}_{2} \mathrm{O}_{3}$ and $\mathrm{Cr}_{2} \mathrm{~N}$, respectively, were found during the first rapid expansion. This event is comparable to the first mass gain discontinuity during TGA. Therefore, $83 \%$ of the mass gain during the first sample expansion and therefore first TGA discontinuity is related to the formation of $\mathrm{Cr}_{2} \mathrm{~N}$ [8]. Interestingly, the fraction of $\mathrm{Cr}_{2} \mathrm{~N}$ formation (83\%) is close to the fraction of $\mathrm{N}_{2}$ in air (78\%). Assuming the difference between both values is attributed to measurement inaccuracies, the $P$-value can be estimated using the following equation:

$$
P=\frac{m\left(\mathrm{Cr}_{2} \mathrm{O}_{3}\right)+m\left(\mathrm{Cr}_{2} \mathrm{~N}\right)}{A} \text { with } m\left(\mathrm{Cr}_{2} \mathrm{O}_{3}\right)=\varphi\left(\mathrm{O}_{2}\right) \cdot m\left(\mathrm{Cr}_{2} \mathrm{~N}\right)
$$

$m(X)=$ mass of species $X$

$A=$ exposed surface area

$\varphi\left(\mathrm{O}_{2}\right)=$ volume fraction of $\mathrm{O}_{2}$ in surrounding atmosphere

In the case of synthetic air $\varphi\left(\mathrm{O}_{2}\right)$ is set to $21 \%$. As previously discussed $k_{\text {para }}$ represents the growth rate of the oxide scale and is most probably not affected by nitridation. Hence, the mass gain caused by nitridation is only addressed by the $P$-value. Using Eq. 8, the formation of brittle $\mathrm{Cr}_{2} \mathrm{~N}$ in the subsurface zone can be estimated by only taking the $P$-value into account. This method is a non-destructive analysis method and therefore offers further possibilities of subsequent investigations of the oxidised material.

\section{Oxidation and Nitridation Mechanism of $\mathrm{Cr}$ and its Alloys}

Figure 7 shows the proposed mechanism of combined oxidation and nitridation of $\mathrm{Cr}$ and its alloys (comparable to Fig. 3). (I) Initially, a thin attached oxide scale forms following paralinear kinetics. (II) During the ongoing exposure and $\mathrm{Cr}_{2} \mathrm{O}_{3}$ formation high growth stresses tend to develop since the Pilling-Bedworth ratio is 2.05 for $\mathrm{Cr}_{2} \mathrm{O}_{3}$ formation on pure $\mathrm{Cr}$ [1]. Thus, the volume more than doubles by oxidising the metal substrate. Additionally, the defect structure of $\mathrm{Cr}_{2} \mathrm{O}_{3}$ strongly depends on the oxygen partial pressure leading to oxygen and chromium counter diffusion [76-79]. Therefore, vacancies recombine within the scale causing pore formation and new $\mathrm{Cr}_{2} \mathrm{O}_{3}$ forms on both scale interfaces and grows simultaneously parallel and perpendicular to the metal surface [21, 80]. All this leads to large stresses within the oxide scale. As the $\mathrm{Cr} / \mathrm{Cr}_{2} \mathrm{O}_{3}$ interface is intrinsically weak [52, 81], stresses are released by scale detachment and scale wrinkling [3]. In the case of scale wrinkling the $\mathrm{Cr}_{2} \mathrm{O}_{3}$ scale detaches from the metal surface and volatile $\mathrm{Cr}_{(g)}$ fills the gap. The volatile $\mathrm{Cr}$ is not immediately oxidised because the oxygen partial pressure at 


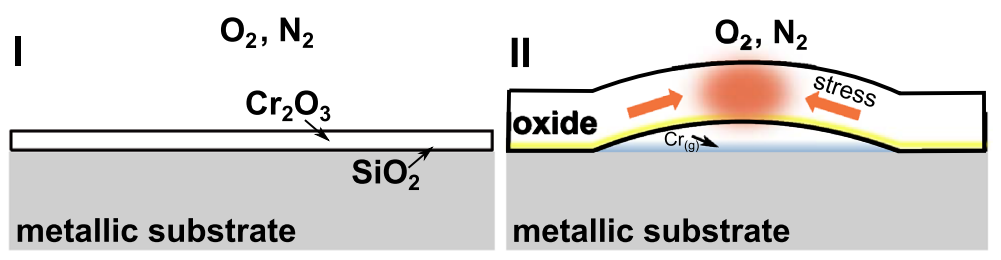

(a) initial oxide grow $\mathrm{h}$

(b) scale detachment and gap formation

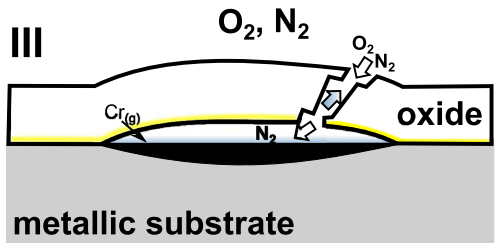

(c) crack formation and nitridation

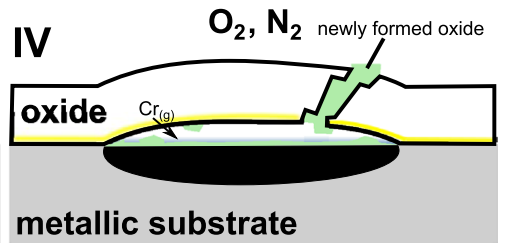

(d) after crack formation

Fig. 7 Mechanism of combined oxidation and nitridation in the case of oxide growth kinetics with mass gain discontinuities. The different steps (I to IV) refer to Fig. 2. This mechanism is based on the descriptions in $[2,8,74]$. (Color online)

the oxide/metal interface is too low [6]. (III) In the case of an oxide scale failure event after wrinkling, $\mathrm{O}_{2}$ and $\mathrm{N}_{2}$ can enter the formed crack and the gap below the oxide scale. Due to the observations made in previous works, crack formation is considered as the dominant mechanism for stress growth release for $\mathrm{Cr}$ and its alloys and therefore solely considered in this description. [8, 74, 75, 82]. In this case, the oxygen partial pressure rises locally at the metal surface. The volatile $\mathrm{Cr}_{(g)}$ which previously filled the gap and the metal surface is oxidised which closes the crack again. The increased $\mathrm{Cr}_{2} \mathrm{O}_{3}$ formation leads to an increased mass gain for the time the crack is closing. Additionally, $\mathrm{N}_{2}$ which previously entered the gap, reacts with $\mathrm{Cr}$ and forms $\mathrm{Cr}_{2} \mathrm{~N}$ [8]. The formation of $\mathrm{Cr}_{2} \mathrm{~N}$ depends on (i) the area of uncovered metal surface and thereby the detachment of the oxide scale during wrinkling and (ii) the tendency to form cracks in the oxide scale to enable nitrogen access. The rapid mass gain ends when the formed oxide scale closes (IV in Fig. 7) and when all nitrogen trapped in the gap is consumed to form $\mathrm{Cr}_{2} \mathrm{~N}$.

\section{Limitations and Future investigations}

The model can be easily implemented for the analysis of isothermal thermogravimetric experiments which are also the classical method to record spontaneous mass gain discontinuities. At present, investigations on the effect of spontaneous and local mass gains on oxidation kinetics are limited. Therefore, lifetime prediction using the $k_{\text {para }}-k_{\text {lin }}-P$-model are challenging. Up to now $P$ and $f_{P}$ were only compared after a certain oxidation time (in this work $100 \mathrm{~h}$ ). To predict the material behaviour also for longer oxidation times a detailed investigation of the link between the mass gain in relation to the number of mass gain discontinuities $\frac{P}{f_{P}}$ and the oxidation time is necessary. For a prediction, a constant ratio $\frac{P_{0}}{f_{P} 0}$ and corresponding probability has to 
be determined. $P$ shows the tendency to increase with increasing time (compare Figs. 1, 4, and 5) and also with increasing time intervals between two mass gain discontinuities. However, up to now, it is not clear which rate law $K(t)$ the ratio of $\frac{P_{0}}{f_{P} 0}$ follows. This has to be investigated in detail in future by determining $P$ and $f_{P}$ after different oxidation times. Knowing $K(t)$, kinetics including mass gain discontinuities can be predicted by modifying Eq. 6:

$$
\frac{\Delta m}{A}=\left(k_{\text {para }} \cdot t\right)^{0.5}-k_{\text {lin }} \cdot t+K(t) \frac{P_{0}}{f_{P} 0}
$$

At present, the model is most useful post-exposure for a better understanding of oxidation and nitridation mechanisms of Cr-based alloys. The application to other systems showing the formation of volatile species during oxidation, oxide scale failure, or change in subsurface zone composition due to the reaction with the surrounding atmospheres (carbide or nitride formation) has to be demonstrated.

\section{Conclusions}

In this work a novel approach to describe oxidation kinetics of materials showing paralinear behaviour interrupted by rapid mass gain discontinuities is introduced. This model includes the determination of a parabolic rate constant (named $k_{\text {para }}$ ) and a volatilisation rate (named $k_{\operatorname{lin}}$ ). The $k_{\text {para }}$ value displays the parabolic growth of the oxide scale independently of the number of formed oxide species. $k_{\text {lin }}$ is the linear evaporation rate of all formed volatile oxidation products. The novelties which distinguishes this model from previous approaches are (i) that $k_{\text {para }}$ and $k_{\text {lin }}$ are determined independently of the rapid mass gain discontinuities and (ii) the introduction of two further parameters, the $P$-value and its frequency $f_{p}$, which describe the rapid mass gain events separately. The $P$-value gives the overall mass change of all discontinuity events, while $f_{P}$ describes the frequency of mass gain discontinuities during a certain oxidation time and can be used as a measure for oxide scale failure.

The application of the $k_{\text {para }}-k_{\operatorname{lin}}-P$-model was demonstrated on the oxidation of pure $\mathrm{Cr}$ and $\mathrm{Cr}-\mathrm{Si}$-alloys for $100 \mathrm{~h}$ at $1200^{\circ} \mathrm{C}$ in synthetic air. By using the developed model, it can be demonstrated that the intrinsic oxide growth kinetic, described by $k_{\text {para }}$ and $k_{\text {lin }}$, can be separated from oxidation during scale failure events and $\mathrm{Cr}_{2} \mathrm{~N}$ formation in the subsurface region of the alloy which also causes mass gain. As $\mathrm{Cr}_{2} \mathrm{~N}$ formation only takes place during rapid mass gains, its effect on the kinetic is fully covered by the newly introduced $P$-value. Depending on the $\mathrm{O}_{2} / \mathrm{N}_{2}$ ratio in the surrounding atmosphere, the fraction of $P$ covering $\mathrm{Cr}_{2} \mathrm{~N}$ formation can be determined. Besides the new insights gained into $\mathrm{Cr}_{2} \mathrm{~N}$ formation, the $k_{\text {para }}-k_{\text {lin }}-P$-model has the advantage that longer exposure times can be considered to determine the paralinear parameters $k_{\text {para }}$ and $k_{\text {lin }}$. On the example of the evolution of the vaporisation constant over oxidation time it was demonstrated, that considering longer exposure times increases the accuracy of the rate constants. Therefore, the application of the $k_{\text {para }}-k_{\text {lin }}-P$-model has the potential to 
reduce the scattering of oxidation constants determined for alloys showing alternating areas of different oxidations rates and two competing mechanisms.

Acknowledgements The authors thank Dr. Rick Durham from DECHEMA e.V. in Frankfurt a.M., Germany, for proof reading.

Author Contributions Anke S. Ulrich involved in methodology, investigation, writing of the original draft preparation, and project administration. Uwe Glatzel participated in validation, supervision, project administration, and funding acquisition. Mathias C. Galetz involved in conceptualisation, supervision, project administration, and funding acquisition

Funding Open Access funding enabled and organized by Projekt DEAL. This work was supported by the Deutsche Forschungsgemeinschaft (DFG) under Grant GL 181/45-1 and GA 1704/2-1.

Availability of Data and Materials Not applicable.

\section{Declarations}

Conflict of interest The authors declare that they have no conflict of interest.

Code Availability Not applicable.

Open Access This article is licensed under a Creative Commons Attribution 4.0 International License, which permits use, sharing, adaptation, distribution and reproduction in any medium or format, as long as you give appropriate credit to the original author(s) and the source, provide a link to the Creative Commons licence, and indicate if changes were made. The images or other third party material in this article are included in the article's Creative Commons licence, unless indicated otherwise in a credit line to the material. If material is not included in the article's Creative Commons licence and your intended use is not permitted by statutory regulation or exceeds the permitted use, you will need to obtain permission directly from the copyright holder. To view a copy of this licence, visit http://creativecommons.org/licen ses/by/4.0/.

\section{References}

1. R. Bürgel, H. J. Jürgen and T. Niendorf, Handbuch Hochtemperatur-Werkstofftechnik, 5, (Springer, Auflage, 2011).

2. L. Royer, X. Ledoux, S. Mathieu and P. Steinmetz, On the oxidation and nitridation of chromium at $1300^{\circ}$ C. Oxidation of Metals 74, (1-2), 2010 (79-92).

3. A. S. Dorcheh, M. Schütze and M. C. Galetz, Factors affecting isothermal oxidation of pure chromium in air. Corrosion Science 130, 2018 (261-269).

4. A. S. Ulrich, P. Pfizenmaier, A. Solimani, U. Glatzel and M. C. Galetz, Improving the oxidation resistance of Cr-Si-based alloys by ternary alloying. Corrosion Science 165, 2020 (108376).

5. D. Caplan and G. Sproule, Effect of oxide grain structure on the high-temperature oxidation of Cr. Oxidation of Metals 9, (5), 1975 (459-472).

6. K. Lillerud and P. Kofstad, On high temperature oxidation of chromium I. Oxidation of annealed, thermally etched chromium at $800-1100^{\circ} \mathrm{C}$. Journal of the electrochemical society 127.11, 1980 (2397-2410).

7. A. Soleimani-Dorcheh, Oxidation-nitridation of chromium at high temperatures and its mitigation by alloying, PhD thesis, RWTH Aachen, Lehrstuhl und Institut für Eisenhüttenkunde. Shaker. 2017.

8. A. Solimani, M. Schütze, A. Stark and M. C. Galetz, Nitrogen transport through thermally grown chromia scales. Corrosion Science 145, 2018 (180-190). 
9. H. Evans and R. Lobb, Conditions for the initiation of oxide-scale cracking and spallation. Corrosion Science 24, (3), 1984 (209-222).

10. D. Monceau and D. Poquillon, Continuous thermogravimetry under cyclic conditions. Oxidation of Metals 61, (1-2), 2004 (143-163).

11. H. Evans, Predicting oxide spallation from sulphur-contaminated oxide/metal interfaces. Oxidation of Metals 79, (1-2), 2013 (3-14).

12. H. Evans, Modelling oxide spallation. Materials at High Temperatures 12, (2-3), 1994 (219-227).

13. M. Schütze, Mechanical properties of oxide scales. Oxidation of Metals 44, (1-2), 1995 (29-61).

14. C. Wagner, Beitrag zur Theorie der Anlaufsvorgänge. Zeitschrift für Physikalische Chemie B21, (2), $1933(25-41)$.

15. A. C. S. Sabioni, A. M. Huntz, F. Millot and C. Monty, Self-diffusion in $\mathrm{Cr}_{2} \mathrm{O}_{3}$ III. Chromium and oxygen grain-boundary diffusion in polycrystals. Philosophical Magazine A 66, (3), 1992 (361-374).

16. W. Quadakkers, D. Naumenko, E. Wessel, V. Kochubey and L. Singheiser, Growth rates of alumina scales on $\mathrm{Fe}-\mathrm{Cr}-\mathrm{Al}$ alloys. Oxidation of Metals 61, (1-2), 2004 (17-37).

17. M. Taylor, H. Evans, S. Stekovic and M. Hardy, The oxidation characteristics of the nickel-based superalloy, RR1000, at temperatures of 700-900 C. Materials at High Temperatures 29, (2), 2012 (145-150).

18. S. Cruchley, H. Evans, M. Taylor, M. Hardy and S. Stekovic, Chromia layer growth on a Ni-based superalloy: sub-parabolic kinetics and the role of titanium. Corrosion Science 75, 2013 (58-66).

19. W. C. Hagel, Factors controlling the high-temperature oxidation of chromium. Journal of the Electrochemical Society 109, (3), 1962 (C78-C78).

20. K. Taneichi, T. Narushima, Y. Iguchi and C. Ouchi, Oxidation or nitridation behavior of pure chromium and chromium alloys containing 10 mass $\% \mathrm{Ni}$ or Fe in atmospheric heating. Materials Transactions 47, (10), 2006 (2540-2546).

21. P. Kofstad, High Temperature Corrosion, vol. 1, (Springer, Berlin, 1988).

22. A. S. Khanna, Introduction to High Temperature Oxidation and Corrosion. ASM International, 2002.

23. D. Caplan and M. Cohen, The volatilization of chromium oxide. Journal of the Electrochemical Society 108.5, 1961 (438).

24. H. C. Graham and H. Davis, Oxidation/vaporization kinetics of $\mathrm{Cr}_{2} \mathrm{O}_{3}$. Journal of the American Ceramic Society 54, (2), 1971 (89-93).

25. Y. Kim and G. Belton, The thermodynamics of volatilization of chromic oxide: Part I. The species $\mathrm{CrO}_{3}$ and $\mathrm{CrO}_{2} \mathrm{OH}$. Metallurgical Transactions 5.8, 1974 (1811-1816).

26. W. H. Smith and A. Seybolt, Ductile chromium. Journal of the Electrochemical Society 103, (6), 1956 (347-352).

27. Y. Gu, H. Harada and Y. Ro, Chromium and chromium-based alloys: problems and possibilities for high-temperature service. JOM 56, (9), 2004 (28-33).

28. A. S. Dorcheh and M. C. Galetz, Challenges in developing oxidation-resistant chromium-based alloys for applications above $900^{\circ}$ C. JOM 68, (11), 2016 (2793-2802).

29. G. Hultquist, B. Tveten and E. Hörnlund, Hydrogen in chromium: influence on the high-temperature oxidation kinetics in $\mathrm{H}_{2} \mathrm{O}$, oxide-growth mechanisms, and scale adherence. Oxidation of Metals 54, (1-2), $2000(1-10)$.

30. S. Saunders, M. Monteiro and F. Rizzo, The oxidation behaviour of metals and alloys at high temperatures in atmospheres containing water vapour: a review. Progress in Materials Science 53, (5), 2008 (775-837).

31. C. Cotell, G. Yurek, R. Hussey, D. Mitchell and M. Graham, The influence of grain-boundary segregation of $\mathrm{Y}$ in $\mathrm{Cr}_{2} \mathrm{O}_{3}$ on the oxidation of Cr metal. Oxidation of Metals 34, (3-4), 1990 (173-200).

32. M. Michalik, M. Hänsel, and W. J. Quadakkers, Effect of water vapour on growth and adherence of chromia scales on pure chromium, Ph.D. thesis. Forschungszentrum, Zentralbibliothek. 2007.

33. P. Fox, D. Lees and G. W. Lorimer, Sulfur segregation during the high-temperature oxidation of chromium. Oxidation of Metals 36, (5-6), 1991 (491-491).

34. P. Kofstad and K. Lillerud, On high temperature oxidation of chromium II. Properties of and the oxidation mechanism of chromium. Journal of the Electrochemical Society 127, (11), 1980 (2410-2419).

35. K. Lillerud and P. Kofstad, Chromium transport through $\mathrm{Cr}_{2} \mathrm{O}_{3}$ scales. II. Changes in scale morphology during high vacuum treatment of oxidized chromium specimens. Oxidation of Metals 17.3-4, 1982 (195-203). 
36. S. Roure, F. Czerwinski and A. Petric, Influence of $\mathrm{CeO}_{2}$-coating on the high-temperature oxidation of chromium. Oxidation of Metals 42, (1), 1994 (75-102).

37. E. Gulbransen and K. Andrew, A preliminary study of the oxidation and vapor pressure of chromium. Journal of the Electrochemical Society 99, (10), 1952 (402-406).

38. L. Cadiou and J. Paidassi, Contribution to the study of the reaction of chromium with oxygen at elevated temperatures. Mem. Sci. Rev. Met. 66, (3), 1969 (217-225).

39. C. Phalnikar, E. Evans and W. Baldwin, High temperature scaling of cobalt-chromium alloys. Journal of the Electrochemical Society 103, (8), 1956 (429-438).

40. C. Tedmon, The effect of oxide volatilization on the oxidation kinetics of $\mathrm{Cr}$ and $\mathrm{Fe}-\mathrm{Cr}$ alloys. Journal of the Electrochemical Society 113, (8), 1966 (766-768).

41. H. Taimatsu, Kinetic analysis of high-temperature oxidation of metals accompanied by scale volatilization. Journal of the Electrochemical Society 146, (10), 1999 (3686-3689).

42. M. P. Brady, P. F. Tortorelli, E. A. Payzant and L. R. Walker, Oxidation behavior of $\mathrm{Cr}_{2} \mathrm{~N}, \mathrm{CrNbN}$, and $\mathrm{CrTaN}$ phase mixtures formed on nitrided $\mathrm{Cr}$ and laves-reinforced $\mathrm{Cr}$ alloys. Oxidation of Metals 61, (5-6), 2004 (379-401).

43. L. Royer, Élaboration et caractérisation d'alliages base chrome pour applications à très haute température, $\mathrm{PhD}$ thesis, Université de Lorraine. 2009.

44. A. Bhowmik, H. T. Pang, S. Neumeier, H. J. Stone, and I. Edmonds, Microstructure and oxidation resistance of Cr-Ta-Si alloys, MRS Online Proceedings Library Archive, 1295 (2011).

45. A. Soleimani-Dorcheh, W. Donner and M. Galetz, On ultra-high temperature oxidation of $\mathrm{Cr}-\mathrm{Cr}_{3} \mathrm{Si}$ alloys: effect of germanium. Materials and Corrosion 65, (12), 2014 (1143-1150).

46. A. Soleimani-Dorcheh and M. C. Galetz, Oxidation and nitridation behavior of $\mathrm{Cr}-\mathrm{Si}$ alloys in air at 1473 K. Oxidation of Metals 84, (1-2), 2015 (73-90).

47. I. Murris, Y. Jacob, V. Haanappel and M. Stroosnijder, High-temperature oxidation behavior of chromium: effect of different batches. Oxidation of Metals 55, (3-4), 2001 (307-331).

48. E. J. Opila, Volatility of common protective oxides in high-temperature water vapor: current understanding and unanswered questions. Materials Science Forum, Trans Tech Publ 461, 2004 (765-774).

49. G. R. Holcomb, Calculation of reactive-evaporation rates of chromia. Oxidation of Metals 69, (3-4), 2008 (163-180).

50. B. Rammer and M. Galetz, Kinetics of volatilization of high temperature corrosion products and its application to chlorine corrosion. Materials and Corrosion 68, (2), 2017 (186-196).

51. N. S. Jacobson, M. A. Kuczmarski and B. A. Kowalski, Vaporization of protective oxide films into different gas atmospheres. Oxidation of Metals 93, (3), 2020 (247-282).

52. M. Schütze, Mechanical aspects of high-temperature oxidation. Corrosion Science 35, (5-8), 1993 (955-963).

53. M. Schütze, P. F. Tortorelli and I. G. Wright, Development of a comprehensive oxide scale failure diagram. Oxidation of Metals 73, (3-4), 2010 (389-418).

54. M. Schütze, Protective Oxide Scales and their Breakdown, (Wiley, London, 1997).

55. C. E. Lowell, C. A. Barrett, R. W. Palmer, J. V. Auping and H. B. Probst, COSP: a computer model of cyclic oxidation. Oxidation of Metals 36, (1-2), 1991 (81-112).

56. J. L. Smialek and J. V. Auping, COSP for windows-strategies for rapid analyses of cyclic-oxidation behavior. Oxidation of Metals 57, (5-6), 2002 (559-581).

57. D. Poquillon and D. Monceau, Application of a simple statistical spalling model for the analysis of high-temperature, cyclic-oxidation kinetics data. Oxidation of Metals 59, (3-4), 2003 (409-431).

58. J. L. Smialek, Oxide morphology and spalling model for NiAl. Metallurgical Transactions A 9, (3), 1978 (309-320).

59. J. L. Smialek, A deterministic interfacial cyclic oxidation spalling model. Acta Materialia 51, (2), 2003 (469-483).

60. C. E. Lowell and D. L. Deadmore, The role of thermal shock in cyclic oxidation. Oxidation of Metals 14, (4), 1980 (325-336).

61. C. A. Barrett and C. E. Lowell, Resistance of $\mathrm{Ni}-\mathrm{Cr}-\mathrm{Al}$ alloys to cyclic oxidation at 1100 and $1200^{\circ}$ C. Oxidation of Metals 11, (4), 1977 (199-223).

62. C. A. Barrett, A. F. Presler, COREST: a FORTRAN computer program to analyze paralinear oxidation behavior and its application to chromic oxide forming alloys, NASA technical note (1976)

63. A. Bhowmik, H. T. Pang, I. M. Edmonds, C. M. Rae and H. J. Stone, Effect of silicon additions on the high temperature oxidation behaviour of $\mathrm{Cr}-\mathrm{Cr}_{2}$ Ta alloys. Intermetallics 32, 2013 (373-383). 
64. A. S. Ulrich, P. Pfizenmaier, A. Solimani, U. Glatzel and M. C. Galetz, Strengthened Cr-Si-base alloys for high temperature applications. International Journal of Refractory Metals and Hard Materials 76, 2018 (72-81).

65. P. Pfizenmaier, A. S. Ulrich, M. C. Galetz and U. Glatzel, Determination of heat treatment parameters by experiments and CALPHAD for precipitate hardening of $\mathrm{Cr}$-alloys with $\mathrm{Si}$, $\mathrm{Ge}$ and $\mathrm{Mo}$. Intermetallics 116, 2020 (106636).

66. A. Solimani, T. Nguyen, J. Zhang, D. J. Young, M. Schütze, M. C. Galetz, Morphology of oxide scales formed on chromium-silicon alloys at high temperatures, Corrosion Science 176 (2020).

67. A. U. Seybolt and D. H. Haman, Oxidation-nitrification of chromium at $1000^{\circ} \mathrm{C}$ Transactions of the Metallurgical Society of AIME, 230.6, p. 1294 (1964)

68. B. E. Deal and A. Grove, General relationship for the thermal oxidation of silicon. Journal of Applied Physics 36, (12), 1965 (3770-3778).

69. D. J. Young, High Temperature Oxidation and Corrosion of Metals, vol. 1, (Elsevier, Amsterdam, 2008).

70. A. Yamauchi, K. Kurokawa and H. Takahashi, Evaporation of $\mathrm{Cr}_{2} \mathrm{O}_{3}$ in atmospheres containing $\mathrm{H}_{2}$ O. Oxidation of Metals 59, (5-6), 2003 (517-527).

71. A. Stenzel, D. Fähsing, M. Schütze and M. C. Galetz, Volatilization kinetics of chromium oxide, manganese oxide, and manganese chromium spinel at high temperatures in environments containing water vapor. Materials and Corrosion 70, (8), 2019 (1426-1438).

72. D. Fähsing, M. Rudolphi, L. Ludmila and M. C. Galetz, Fireside corrosion of chromium-and aluminum-coated ferritic-martensitic steels. Oxidation of Metals 88, (1-2), 2017 (155-164).

73. N. Birks, G. H. Meier and F. S. Pettit, Introduction to the High Temperature Oxidation of Metals, (Cambridge University Press, Cambridge, 2006).

74. A. S. Ulrich, Entwicklung von ausscheidungshärtbaren $\mathrm{Cr}-\mathrm{Si}$-Basis-Legierungen für Hochtemperaturanwendungen: Mikrostruktur und Oxidation, PhD thesis, Universität Bayreuth. Shaker. 2020.

75. A. S. Ulrich, T. Kaiser, E. Ionescu, R. Riedel and M. C. Galetz, Reactive element effect applied by alloying and SiHfBCN coating on the oxidation of pure chromium. Oxidation of Metals 92, (3-4), 2019 (281-302).

76. X. Ledoux, S. Mathieu, M. Vilasi, Y. Wouters, P. Del-Gallo and M. Wagner, Oxide growth characterization during short-time oxidation of a commercially available chromia-forming alloy (HR-120) in air at $1050^{\circ}$ C. Oxidation of Metals 80, (1-2), 2013 (25-35).

77. L. Latu-Romain, S. Mathieu, M. Vilasi, G. Renou, S. Coindeau, A. Galerie and Y. Wouters, The role of oxygen partial pressure on the nature of the oxide scale on a NiCr model alloy. Oxidation of Metals 88, (3-4), 2017 (481-493).

78. L. Latu-Romain, Y. Parsa, S. Mathieu, M. Vilasi, A. Galerie and Y. Wouters, Towards the growth of stoichiometric chromia on pure chromium by the control of temperature and oxygen partial pressure. Corrosion Science 126, 2017 (238-246).

79. A. Huntz and S. Tsai, Diffusion in oxide scales: application to $\mathrm{Cr}_{2} \mathrm{O}_{3}$ scales. Journal of Materials Science Letters 13, (11), 1994 (821-825).

80. L. Latu-Romain, Y. Parsa, S. Mathieu, M. Vilasi, M. Ollivier, A. Galerie and Y. Wouters, Duplex n-and p-type chromia grown on pure chromium: a photoelectrochemical and microscopic study. Oxidation of Metals 86, (5-6), 2016 (497-509).

81. P. Y. Hou and J. Stringer, Oxide scale adhesion and impurity segregation at the scale/metal interface. Oxidation of Metals 38, (5-6), 1992 (323-345).

82. H. E. Evans, Stress effects in high temperature oxidation of metals. International Materials Reviews 40, (1), 1995 (1-40).

Publisher's Note Springer Nature remains neutral with regard to jurisdictional claims in published maps and institutional affiliations. 